\title{
Effect of Annealing on the Structural and Magnetic Properties of 3\% Sm Doped ZnO
}

\author{
Hanan Hassan Hantour*, Nadia Abd El-Mohsen, Suzan Naser El-Sayed, \\ Assma Mahmoud Aoud Mahmoud
}

Physics Department, Faculty of Science, Al-Azhar University (Girls), Cairo, Egypt

Email address:

hananhantourmy@yahoo.com (H. H. Hantour)

${ }^{*}$ Corresponding author

\section{To cite this article:}

Hanan Hassan Hantour, Nadia Abd El-Mohsen, Suzan Naser El-Sayed, Assma Mahmoud Aoud Mahmoud. Effect of Annealing on the Structural and Magnetic Properties of 3\% Sm Doped ZnO. International Journal of Electrical Components and Energy Conversion. Vol. 4, No. 1, 2018, pp. 13-20. doi: 10.11648/j.ijecec.20180401.12

Received: December 28, 2017; Accepted: January 30, 2018; Published: February 26, 2018

\begin{abstract}
The present study focuses on the structural and magnetic properties of Sm doped $\mathrm{ZnO}$ at $3 \%$ concentrations. These compounds have been synthesized by a chemical coprecipitation method and characterized by X-ray diffraction (XRD), scanning electron microscopy (SEM), transmission electron microscopy (TEM) and magnetization method (M- H). The XRD pattern of all the samples showed $\mathrm{ZnO}$ hexagonal wurtzite structure with sharp and intense peaks with small change in lattice parameters due to $\mathrm{Sm}$ doping in $\mathrm{ZnO}$, indicating the substitution of $\mathrm{Sm}$ ion for $\mathrm{Zn}$ sites. Magnetic measurements show an enhancement in room temperature ferromagnetism (RTFM) with Sm doping. Ferromagnetic behavior exists over and above the diamagnetic behavior, RTFM related to The Zn vacancies and diamagnetic (which exists over alarge scale) related to the oxygen vacancies which mediate the interaction of dopant ions.
\end{abstract}

Keywords: ZnO, Nanoparticles, Semiconductors, Magnetic Materials, Zinc Vacancy, Structure, Microstructure, Magnetic with Different Temperature

\section{Introduction}

$\mathrm{ZnO}$ due to its wide direct band-gap $(3.37 \mathrm{eV})$, large exciton energy $(60 \mathrm{meV})$, chemical and thermal stability as well as low toxicity is considered to have important properties in basic and applied researches [1-5]. Oxide semiconductor based diluted magnetic semiconductor (DSM) is one of spintronic materials, which has both semiconductor and magnetic behavior. The magnetic property from the realization of spin functions $[6,7]$. The introduction of impurity atoms into semiconducting materials is the primary method for controlling the properties of the semiconductor, such as band gap or electrical conductivity [8]. Doping is the most effective and efficient way to tune the selectivity of the diluted magnetic semiconductors [9]. Correspondingly, several theoretical models have been developed to explain the coupling mechanism of the magnetic behavior of the samples [10]. The modification of $\mathrm{ZnO}$ properties by doping has become an important research topic in order to improve the intrinsic characteristics of the these materials. Doping of $\mathrm{ZnO}$ allows it's optical and magnetic properties to be adapted, through alteration of its electronic structure and band gap [11]. In general, $\mathrm{ZnO}$ has well separated valence and conduction band. Optical excitation will induce electron-hole pairs where the excitons will form just below the conduction band. These excitons are sensitive to physical and chemical environment in $\mathrm{ZnO}$ structure as well as to the presence of defects and dopant.

TM doped $\mathrm{ZnO}, \mathrm{TM}$ ion interactions play a vital role in controlling the excitation dynamics [12-14], and also, the magnetism is so weak that it is often buried by experimental artifacts and always has the problems of reproducibility or precipitation of secondary metallic phases. Compared with $3 \mathrm{~d}$ transition metals, $4 \mathrm{f}$ rare earth (RE) elements have larger magnetic moments and likely to potentially enhance the ferromagnetism (FM) in doped semiconductors $[15,16]$. Theoretical investigations revealed stable FM coupling between $\mathrm{RE}$ ions are mediated by the delocalized electrons. This is particularly beneficial to $\mathrm{ZnO}$, since it exhibits n-type conductivity with a large population of 's' electrons [17]. The 
influence of RE doping in $\mathrm{ZnO}$ mainly focus on its optical properties. Few reports are available on $\mathrm{RE}$ doped $\mathrm{ZnO}$ nanoparticles which provide information about the density of $\mathrm{RE}$ ions and also the response of the nanoparticles to the applied magnetic field.

\section{Experimental}

Samples of $\mathrm{ZnO}$ and $\mathrm{ZnO}: \mathrm{Sm}$ doped have been prepared by chemical coprecipitation by mixing an appropriate amount of $\mathrm{NaOH}, \mathrm{ZnCl}_{2}$ and $\mathrm{SmCl}_{2}$ prepare $\mathrm{ZnO}$ nanoparticle, $0.5 \mathrm{M}$ aqueous solution of $\mathrm{ZnCl}_{2}$ and $1 \mathrm{M}$ of $\mathrm{NaOH}$ were prepared in deionized water. The method for the preparation of $\mathrm{ZnO}$ nanoparticle is a slight modified method of Abdolmajid et al [18]. $1 \mathrm{M}$ of $\mathrm{NaOH}$ solution was taken in a beaker and heated to $50^{\circ} \mathrm{C}$. After 5 mintes of heating the $\mathrm{NaOH}$ solution, $\mathrm{ZnCl}_{2}$ was added dropwise to the above heated solution under high magnetic stirring. After the complete addition of $\mathrm{ZnCl}_{2}$, the beaker was sealed and kept at stirring condition for $10 \mathrm{~min}$ at $50^{\circ} \mathrm{C}$. The white precipitate formation was observed at above conditions [19]. The precipitation was collected and washedwith deionized water and with $100 \%$ ethanol then air dried at $100^{\circ} \mathrm{C}$. The annealed samples are heated at 400 and $800^{\circ} \mathrm{C}$ for three hours. The X-ray diffraction, using Philips diffractometer (X'pert MPD) goniometer type PW3050/10 with $\mathrm{Cu}-\mathrm{K \alpha}$ radiation source $(\lambda=1.54178 \AA)$; the field emission scanning electron microscopy (FESEM) was performed on JEOL JSM$6700 \mathrm{~F}$ to investigate the surface morphology of the samples. The Vibrating sample magnetometer (VSM) was used to measure the magnetization curve $(\mathrm{M}-\mathrm{H})$ at room temperature. To obtain information on oxidation state and site occupancy of the $\mathrm{Sm}$ and $\mathrm{Li}$ ions in the $\mathrm{ZnO}$ matrix electron spin resonance (ESR) was carried out using X-band JEOL JES-RE1X at room temperature.

\section{Results and Discussion}

\subsection{Structure and Microstructure Analysis}

\subsubsection{XRD Analysis}

Figure 1 indicate The XRD patterns of the $\mathrm{ZnO}$ and $\mathrm{ZnO}$ doped with $3 \% \mathrm{Sm}$ at room temperature and annealing temperature $400^{\circ} \mathrm{C}$ and $800^{\circ} \mathrm{C}$. Sharp and intense peaks corresponding to the hexagonal wurtzite structure of $\mathrm{ZnO}$ with $\mathrm{P}_{3} \mathrm{mc}$ as space group were observed. The sharp peaks indicate that the $\mathrm{ZnO}$ : $\mathrm{Sm}$ possesses a crystalline structure. It may be noted that all peaks of wurtzite $\mathrm{ZnO}$ have their preferred orientation along the (1 001 ) reflection plane for each composition. The comparison of peak positions with the Standard Joint Committee for Powder Diffraction pattern (JCPDS card no. 36-1451) suggests the polycrystalline nature of the system. All the patterns are identified to be a single phase $\mathrm{ZnO}$ with hexagonal structure for all compossions at RT, annealed at $400^{\circ} \mathrm{C}$ and annealing at $800^{\circ} \mathrm{C}$. So Sm ion is completely doped into the $\mathrm{Zn}$ lattice. Tablel gives the refined structural parameters obtained from Rietveld analysis applying the MAUD program.

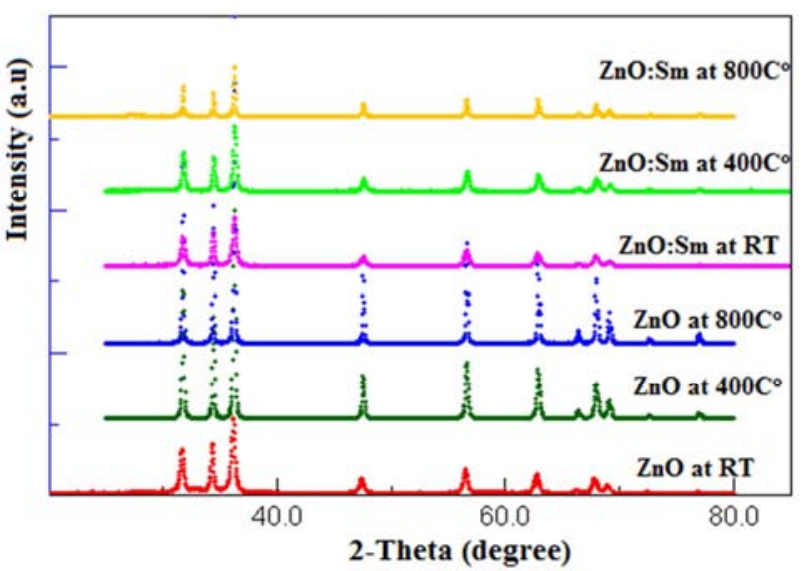

Figure 1. Diffraction pattern of $\mathrm{ZnO}$ and $\mathrm{ZnO}: \mathrm{Sm}$ systems at: (a) Room temperature (RT), (b) $400^{\circ} \mathrm{C}$ and (c) $800^{\circ} \mathrm{C}$.

Figure $2(\mathrm{a}, \mathrm{b})$ illustrate the diffraction patterns fitting resulting from Rietveld analysis of all the compositions at RM (room temperature). During analysis, the site $2 \mathrm{~b}\left(1 / \frac{2}{3} / 30\right)$ occupancy shared by $\mathrm{Zn}$ and $\mathrm{Sm}$, the $\mathrm{Sm}$ ion is incorporated substitutionally in the $\mathrm{ZnO}$ lattice replacing the $\mathrm{Zn}$ ions in the position $2 \mathrm{~b}$. The lattice parameters increase with increasing the percentage of $\mathrm{Sm}$ where the atomic radius of $\mathrm{Sm} 2.59 \mathrm{~A}^{\circ}$ is greater than the atomic radius of $\mathrm{Zn} 1.53 \mathrm{~A}^{\circ}$. Similar c-axis variations have also been reported in $\mathrm{Er}, \mathrm{Sm}$, and Ce doped $\mathrm{ZnO}$. This variation in the lattice parameters occurs due to substitution of the bigger ionic radii of $\mathrm{Sm}^{3+}(0.964 \mathrm{~nm})$ in place of $\mathrm{Zn}^{2+}(0.74 \mathrm{~nm})$.
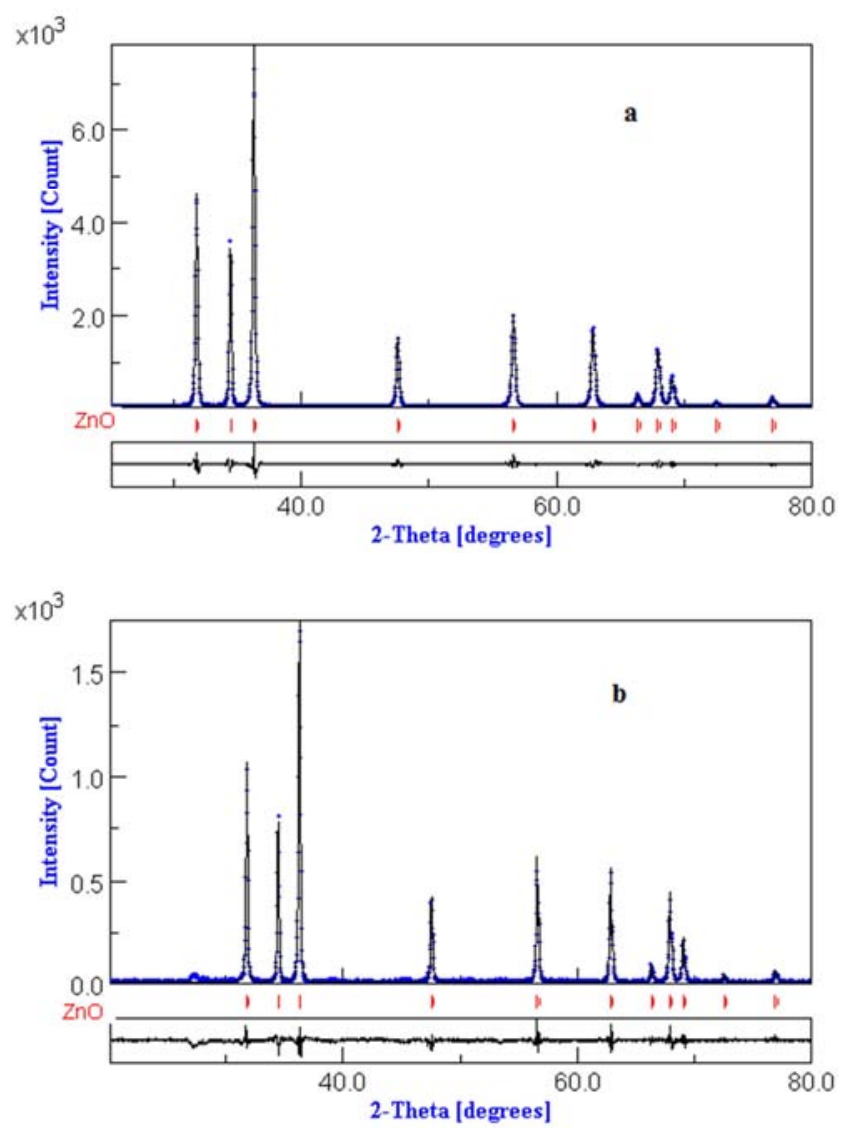

Figure 2. Profile fitting of: (a) $\mathrm{ZnO}$ and (b) $\mathrm{Zn}_{0.97} \mathrm{Sm}_{0.03} \mathrm{O}$. 
The change in the lattice parameter trend reverses with Sm doping which may be associated with the increase in the number of defects due to the substitutional doping of Sm. The parameters a and c depend upon certain factors such as: (i) the concentration of impurity atoms, defects, and the difference between the ionic radii of $\mathrm{Zn}^{2+}$ and the impurity atoms Sm; (ii) external strains developed due to external pressures and temperatures. Thus the reduction in the intensity of the peaks and the change in the lattice parameters is associated with the lattice distortion and strain induced in $\mathrm{ZnO}$ due to the substitution of $\mathrm{Zn}^{2+}$ by $\mathrm{Sm}^{3}$. An appreciable broadening has also been observed in the XRD peaks, along with the crystallite size, lattice strain also contributes to the broadening of the XRD peaks and has been estimated. This strain induced may be due to a change in the lattice parameters with Sm doping.

The information on strain and crystallite size was obtained from Winfit program the crystallites size which is increas with $\mathrm{Sm}$ shown in table1. The internal tetrahedral distortion and the spontaneous polarization in $\mathrm{ZnO}$ can be assessed using the atomic position parameter $(\mathrm{u})$, the nearest neighbor bond length along $\mathrm{c}$ direction (b) and the bond angles $\alpha$ and $\beta$ are average basal bond length $\left(\mathrm{O}_{\mathrm{a}}-\mathrm{Zn}-\mathrm{O}_{\mathrm{b}}\right)$ and average base apex angle $\left(\mathrm{O}_{b}-\mathrm{Zn}-\mathrm{O}_{b}\right)$ respectively where $\mathrm{O}_{a}$ refers $\mathrm{O}$ atom at the apex and $\mathrm{O}_{\mathrm{b}}$ represents $\mathrm{O}$ atom at the base of the tetrahedral structure.

Table 1. The refined lattice parameters ( $a$ and $c$ ) $\left(A^{\circ}\right)$, average $\mathrm{Zn}-\mathrm{O}$ bond lengths $\left(b A^{\circ}\right)$, average bond angle, crystallite size $(L \mathrm{~nm})$ and mean square strain (ع) obtained from Rietveld analysis of $\mathrm{ZnO}$ and $\mathrm{ZnO}: \mathrm{Sm}$ at $\mathrm{RT}$.

\begin{tabular}{lllll}
\hline \multirow{2}{*}{ Parameter } & At RT & \multicolumn{3}{c}{$\mathbf{A t ~} \mathbf{4 0 0}^{\circ} \mathbf{C}$} \\
\cline { 2 - 5 } & $\mathbf{Z n O}$ & $\mathbf{Z n}_{\mathbf{0 . 9}} \mathbf{S m}_{\mathbf{0 . 0 3}} \mathbf{O}$ & $\mathbf{Z n O}$ & $\mathbf{Z n}_{\mathbf{0 . 9 7}} \mathbf{S m}_{\mathbf{0 . 0 3}} \mathbf{O}$ \\
\hline $\mathrm{a}$ & 3.242 & 3.2445 & 3.243 & 3.244 \\
$\mathrm{c}$ & 5.192 & 5.195 & 5.193 & 5.195 \\
$\mathrm{R}_{\mathrm{W}} \%$ & 8.236 & 10.910 & 6.891 & 10.268 \\
$\mathrm{R}_{\mathbf{e x p}} \%$ & 7.528 & 9.327 & 4.749 & 9.313 \\
$\mathrm{u}$ & 0.3802 & 0.3798 & 0.3802 & 0.3798 \\
$\mathrm{~b} \AA$ & 1.985 & 1.984 & 1.985 & 1.984 \\
$\alpha$ & 108.364 & 108.446 & 108.364 & 108.446 \\
$\beta$ & 110.555 & 110.476 & 110.555 & 110.476 \\
$\mathrm{~L}(\mathrm{~nm})$ & 14.1 & 13.3 & 29.9 & 22.3 \\
$\varepsilon \times 10^{-3}$ & 1.28 & 1.32 & 1.32 & 1.36 \\
\hline
\end{tabular}

\subsubsection{Scanning Electron Microscopy (SEM) and High Resolution Transmission Electron Microscopy (HRTEM)}

Figure 3 shows The SEM images show surface morphologies of the $\mathrm{Zn}_{1-\mathrm{x}-\mathrm{y}} \mathrm{Sm}_{\mathrm{x}} \mathrm{Li}_{\mathrm{y}} \mathrm{O}$ samples at RT and annealed at $800^{\circ} \mathrm{C}$. As it follows from the SEM micrographs the synthesized samples consisted of spherical clusters but these images clearly show that the samples annealed at $800^{\circ} \mathrm{C}$ is more homogenous in shape and size than the samples at RT. Results obtained by high resolution transmission electronmicroscopy (HRTEM) are shown in Figure 4, 5, 6. The selected area electron diffraction (SAED) image is shown in Figure 4 these patterns suggest that the $\mathrm{ZnO}$ and doped powder is in crystalline wurtzite structure as revealed by the XRD study. The HRTEM micrographs in
Figure 5 characterized the surface morphology of the samples. It is obvious that these samples are consisting of very good crystallized areas of nanosized. The interlayer spacing $\mathrm{d}=0.2 \mathrm{~nm}$ of the all samples corresponding to the (1 0 1) plane. The morphologies are shown in Figure 6 . The particle sizes are mainly between 25-66 $\mathrm{nm}$, the average crystallite sizes of the samples determined by X-ray diffraction were significantly smaller than the values determined by TEM, which can be attributed to the fact that the values observed by TEM have the size of the secondary particles. In addition, the X-ray line broadening analys is disclosed only the size of a single crystallite.

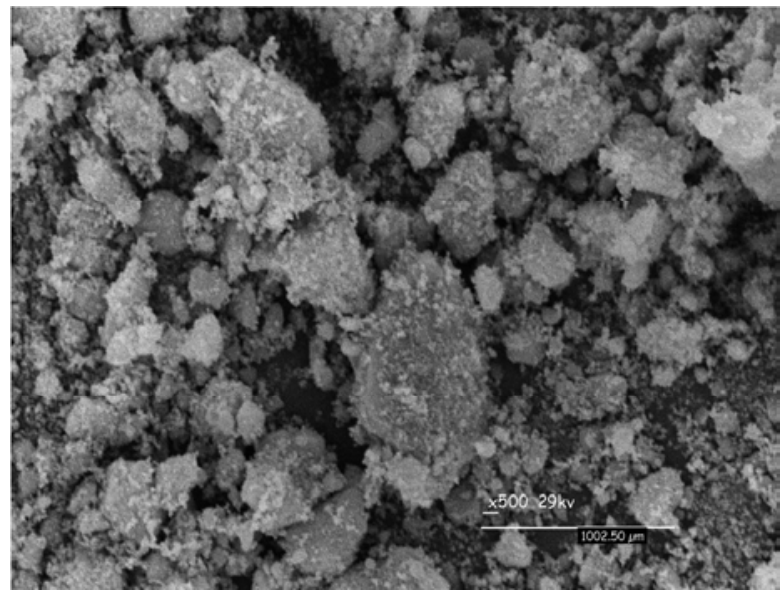

$\mathrm{ZnO}$ at $\mathrm{RM}$

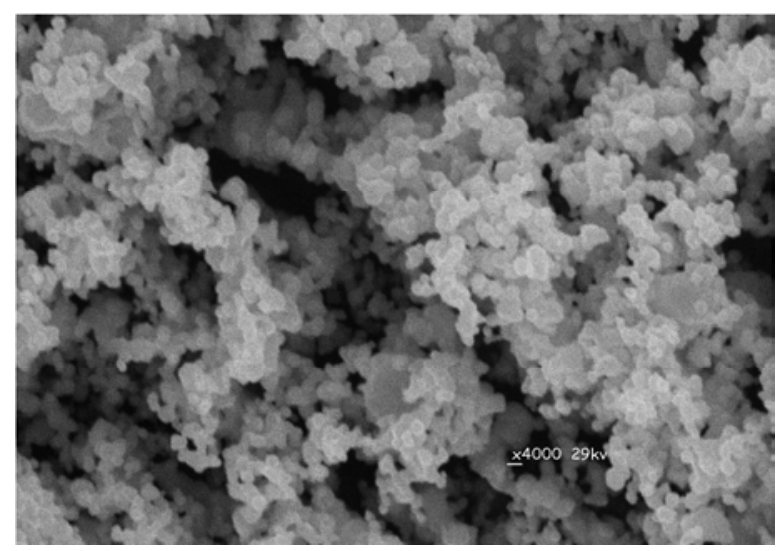

$\mathrm{ZnO}$ at $800^{\circ} \mathrm{C}$

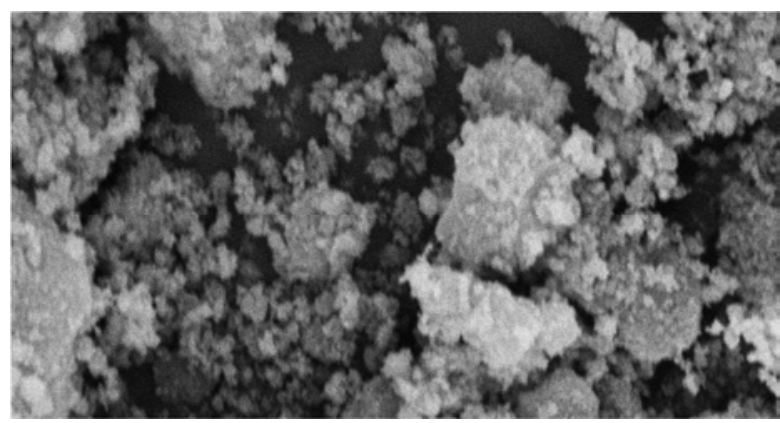

$\mathrm{Zn}_{0.96} \mathrm{Sm}_{0.03} \mathrm{O}$ at $\mathrm{RM}$ 


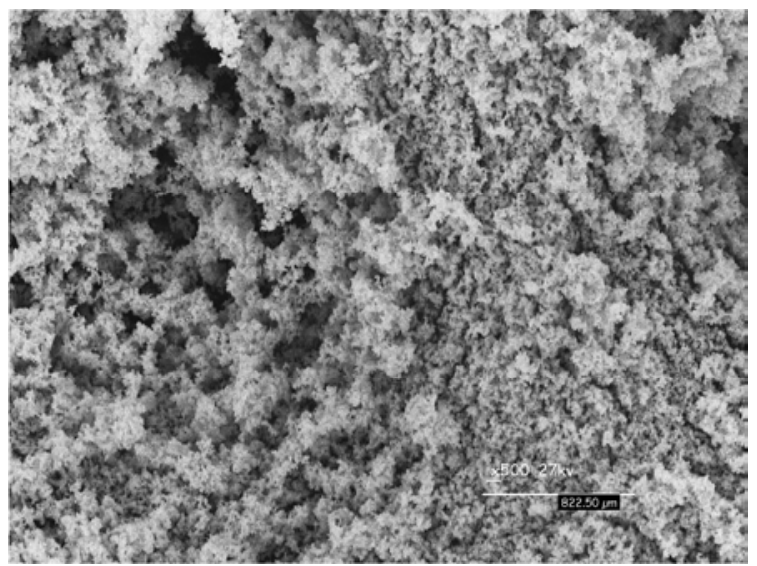

$\mathrm{Zn}_{0.96} \mathrm{Sm}_{0.03} \mathrm{O}$ at $800^{\circ} \mathrm{C}$

Figure 3. SEM of Zn0.96Sm0.03 systems annealing at $R T$ and $800^{\circ} \mathrm{C}$.

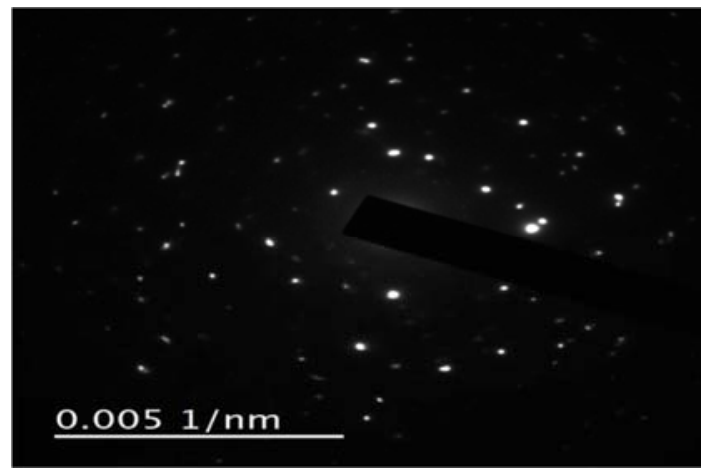

$\mathrm{ZnO}$

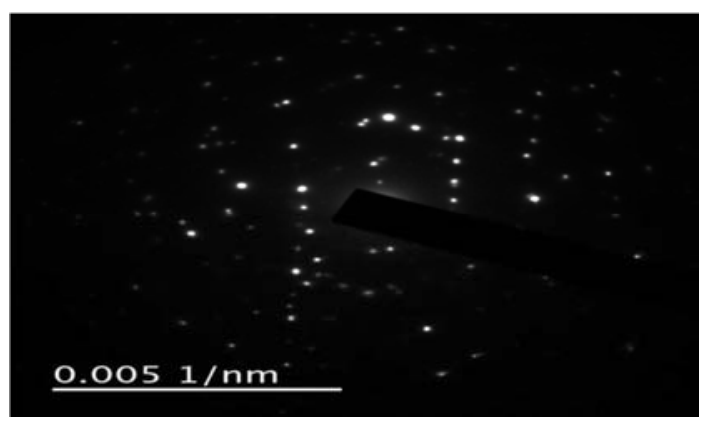

$\mathrm{Zn}_{0.97} \mathrm{Sm}_{0.03} \mathrm{O}$

Figure 4. The selected area electron diffraction (SAED) of Zn0.96Sm0.03 systems.

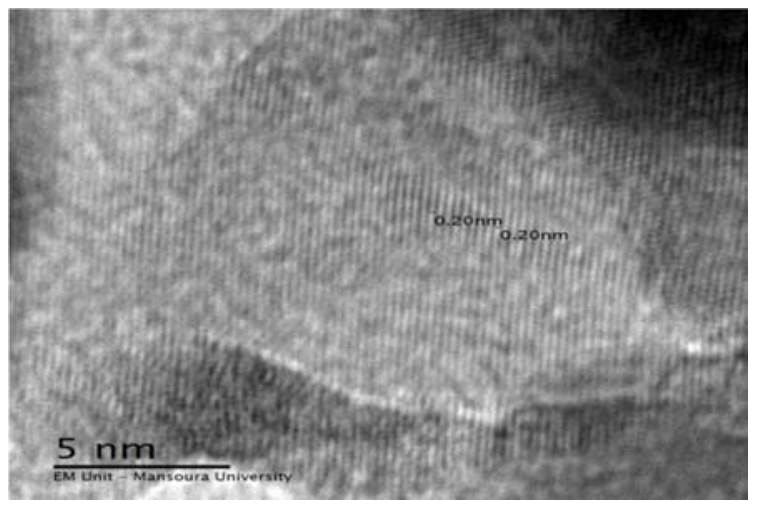

$\mathrm{ZnO}$

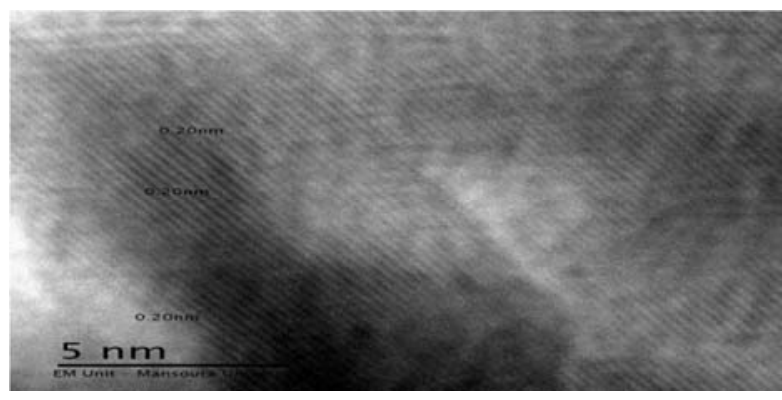

$\mathrm{Zn}_{0.97} \mathrm{Sm}_{0.03} \mathrm{O}$

Figure 5. High resolution TEM of Zn0.96Sm0.03 system.

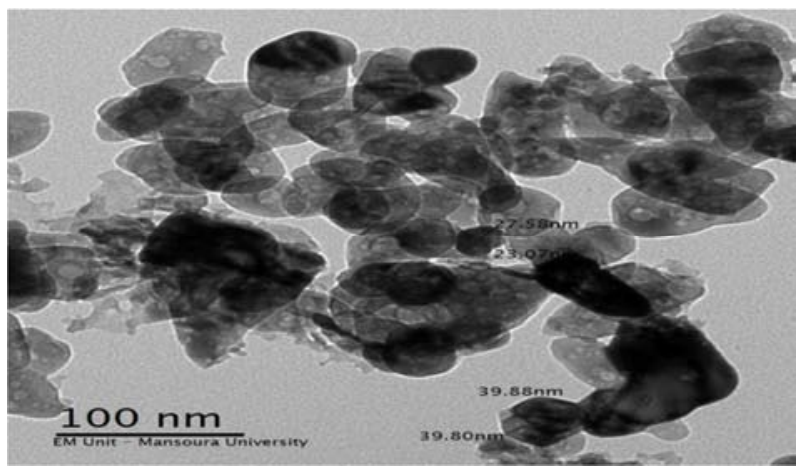

$\mathrm{ZnO}$

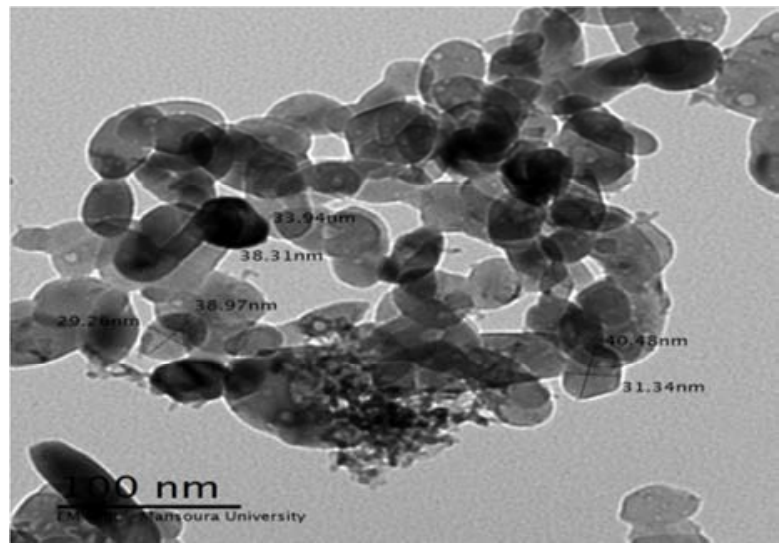

$\mathrm{Zn}_{0.96} \mathrm{Sm}_{0.03} \mathrm{O}$

Figure 6. Transmission electron micrograph of Zn0.96Sm0.03 system.

\subsection{Magnetic Studies}

\subsubsection{VSM Characteristic}

Figure 7 shows de magnetization hysteresis loop of pure $\mathrm{ZnO}$ measured at $\mathrm{RT}$. It is observed that $\mathrm{ZnO}$ nano particles exhibit a ferromagnetic behavior with coercivity $\left(\mathrm{H}_{\mathrm{C}}\right)$ of 286 Oe, saturation magnetization $\left(\mathrm{M}_{\mathrm{S}}\right)$ of $0.973 \mathrm{emu} / \mathrm{g}$ and remnant magnetization $\left(\mathrm{M}_{\mathrm{R}}\right)=0.199 \mathrm{emu} / \mathrm{g}$. Some groups have also reported ferromagnetism in pure $\mathrm{ZnO}$ nano particles and thin films [20-26]. They intend that ferromagnetism is the universal feature of the nano particles of non-magnetic oxides. They explained that the origin of ferromagnetism in these nanoparticles is due to oxygen vacancies. But recently, some theoretical group has reported that ferromagnetism in $\mathrm{ZnO}$ is due to the $\mathrm{Zn}$ vacancies and suggested that the origin of the magnetism does not result 
from the $\mathrm{Zn} 3 \mathrm{~d}$ electron but it is originated from the unpaired $2 \mathrm{p}$ electron of $\mathrm{O}$ atom in the immediate vicinity of $\mathrm{Zn}$ vacancies [24, 27]. Zubiaga et al [28] study defect in $\mathrm{ZnO}$ bulk using positron annihilation life time spectroscopy and reported the presence of $\mathrm{Zn}$ vacancies in pure $\mathrm{ZnO}$. Therefore, the RTFM in pure $\mathrm{ZnO}$ rods are due to the $\mathrm{Zn}$ vacancies induced spin polarization [26].

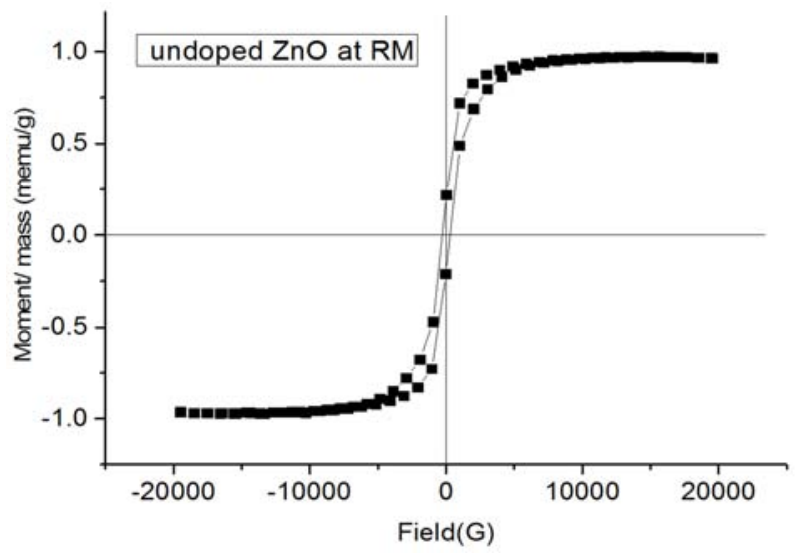

Figure 7. Hysteresis loop of pure $\mathrm{ZnO}$ measured at RT.
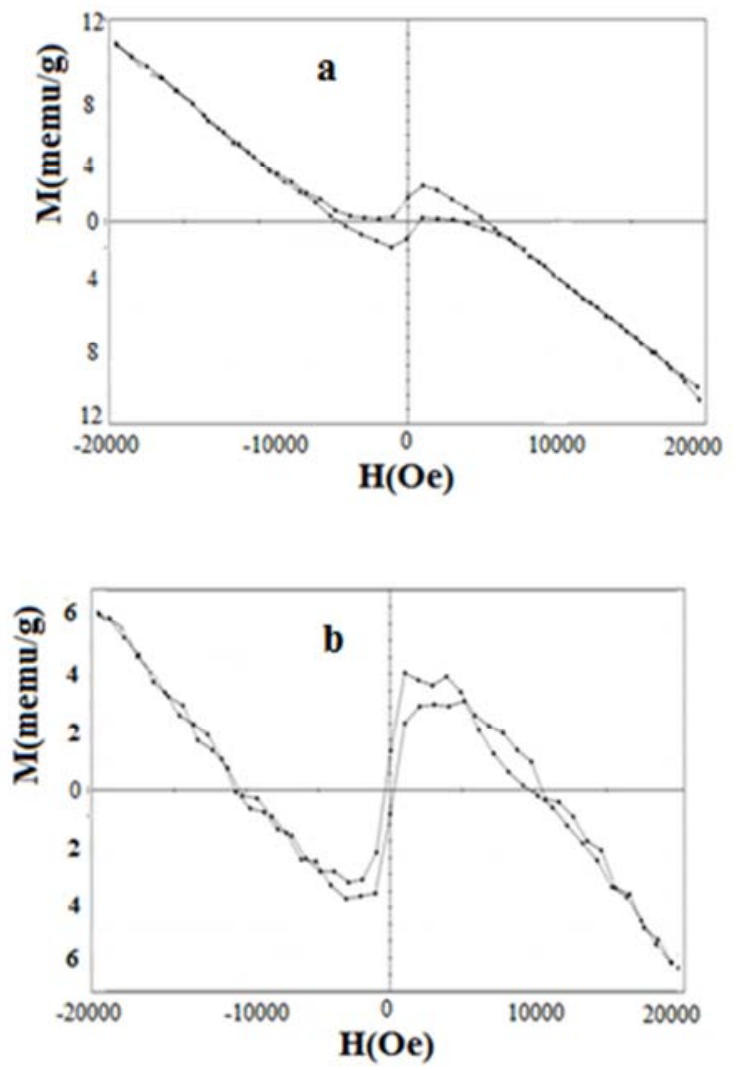

Figure 8. Hysteresis loop of pure $\mathrm{ZnO}$ annealed (a) at $400^{\circ} \mathrm{C}$ and (b)at $800^{\circ} \mathrm{C}$.

After annealing at $400^{\circ} \mathrm{C}$ and $800^{\circ} \mathrm{C}$ the undoped $\mathrm{ZnO}$ sample shows weak ferromagnetic behavior and the values of $H_{C}, M_{S}$ and $M_{R}$ are decreased with increase in the annealing temperature as shown in Figure $8 \mathrm{a}, \mathrm{b}$. With annealing at $400^{\circ} \mathrm{C} \mathrm{H}_{\mathrm{C}}=990 \mathrm{Oe}, \mathrm{M}_{\mathrm{s}}=2.33 \times 10^{-3} \mathrm{emu} / \mathrm{g}$ and $\mathrm{M}_{\mathrm{R}}=1.616 \times 10^{-}$
${ }^{3} \mathrm{emu} / \mathrm{g}$ and at $800^{\circ} \mathrm{C} \mathrm{H}_{\mathrm{C}}=312 \mathrm{Oe}, \mathrm{M}_{\mathrm{s}}=3.643 \times 10^{-3} \mathrm{emu} / \mathrm{g}$ and $\mathrm{M}_{\mathrm{R}}=1.11 \times 10^{-3} \mathrm{emu} / \mathrm{g}$. Quite a few reports [29-31] indicate occurrence of ferromagnetic ordering in nanocrystals of nonmagnetic solids and ions [29] $\left(\mathrm{Zn}^{2+}\right.$ and $\left.\mathrm{O}^{2-}\right)$ due to surface defects. Although there is a possibility of presence of $\mathrm{Zn}$ interstials and oxygen vacancies at surface of undoped $\mathrm{ZnO}$ nanocrystals, these defects are not large enough to induce ferromagnetism in undoped $\mathrm{ZnO}$ nanocrystals [30].

In bound magnetic polarons (BMP) model, the oxygen vacancy as defect mediates the spins of localized electrons of dopant ions in $3 \mathrm{~d}$ state, but the mechanism of FM in pure $\mathrm{ZnO}$ without magnetic ions is not clear. Here, we give simple approach; we believe that the magnetism of undoped $\mathrm{ZnO}$ should be coming from the change in the net spins in the $d$ orbits of $\mathrm{Zn}\left(3 \mathrm{~d}^{10}\right)$. The d-orbits should be uncompleted with unpaired electron $\left(3 d^{9}\right)$ which may be achieved by defects like oxygen vacancy $\left(\mathrm{V}_{\mathrm{O}}\right)$. The $\mathrm{V}_{\mathrm{O}}$ may capture one electron from the complete field-band of $\mathrm{Zn}\left(\mathrm{d}^{10}\right)$ to be uncompleted filled d-orbits that leads to a net spin one-half in $\mathrm{Zn}$ orbits, for stabilization of the system. The magnetic decrease with increase in the annealing temperature. This is directly related to the decrease in $\mathrm{V}_{\mathrm{O}}$ concentration [32].

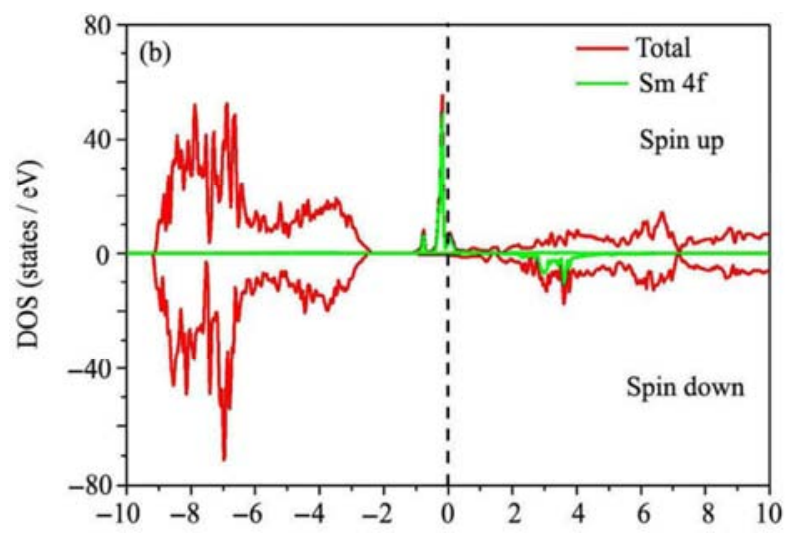

Figure 9. The total DOS of the super cell contains a $\mathrm{Sm}_{\mathrm{Zn}}{ }^{(37)}$.

When we replace one $\mathrm{Zn}$ atom with $\mathrm{Sm}$, and the calculations suggest that one $\mathrm{Sm}$ substitutional $\left(\mathrm{Sm}_{\mathrm{Zn}}\right)$ favors the ferromagnetic ground state with an energy difference of $\mathrm{E}_{\mathrm{AFM}}-\mathrm{E}_{\mathrm{FM}}=296 \mathrm{meV}$ and the total magnetic moment is 0.337 $\mu \mathrm{B}$. Systems with a single zinc vacancy, oxygen interstitial are magnetic as well with moments of $1.75 \mu \mathrm{B}$ and $1.99 \mu \mathrm{B}$, respectively [33]. Abundant Reports have shown that the obtained magnetism in $\mathrm{V}_{\mathrm{Zn}}$ and $\mathrm{O}_{\mathrm{i}}$ originates from the $\mathrm{p}$ orbitals of the oxygen atoms around the defect sites via $p-p$ exchange interaction [34-36]. The total DOS of the super cell contains a $\mathrm{Sm}_{\mathrm{Zn}}$ is illustrated in Figure 9 [37]. For $\mathrm{ZnO}: \mathrm{Sm}$ the $4 \mathrm{f}$ electrons occupy gradually the majority spin $t_{1 \mathrm{~g}}$ states, majority spin $t_{2 g}$ states and majority spin $a_{2 g}$ states, thus the total magnetic moment increases. The $4 \mathrm{f}$ electrons in the majority spin states are totally occupied, and the Fermi level shifts into the conduction band, the electrons occupy gradually the minority spin $\mathrm{t}_{1 \mathrm{~g}}$ states, $\mathrm{t}_{2 \mathrm{~g}}$ states and $\mathrm{a}_{2 \mathrm{~g}}$ states, then the total magnetic moment decreases as shown in Figure 10. Indeed, the $4 \mathrm{f}$ states show a large spin exchange splitting $\varepsilon_{\mathrm{d}}$, i.e.: the energy difference between the centers of majority 
spin and minority spin states and a small crystal field splitting, i.e.: the energy difference between $\mathrm{t}_{1 \mathrm{~g}}$ and $\mathrm{a}_{2 \mathrm{~g}}$ states for one kind of spin. Moreover, the exchange splitting $\varepsilon_{\mathrm{d}}$ is in an increasing order for the rare earth elements, and the crystal field splitting of the majority spin states decreases as the number of $4 \mathrm{f}$ electrons increases [37].

Detailed magnetic measurements were carried out on undoped as well as 3\% $\mathrm{Sm}$ doped $\mathrm{ZnO}$ samples at room temperature with a vibrating sample magnetometer. The magnetization characteristics of the samples are shown in Figure10. Whereas undoped $\mathrm{ZnO}$ showed ferromagnetic behavior the characteristics start changing with doping of $\mathrm{Sm}^{3+}$ in $\mathrm{ZnO}$. With $\mathrm{Sm} \mathrm{3 \%}$ doping, a ferromagnetic loop is seen in the magnetic field region of -6000 to 6000 Gauss over and above the diamagnetic trend as shown in Figure 10. The ferromagnetic behavior is increase with increase annealing temperature at $400^{\circ} \mathrm{C}$ and then decrease with increase the annealing temperature at $800^{\circ} \mathrm{C}$. Experimental observation of existence of ferromagnetism in $\mathrm{ZnO}$ lattice solely due to Sm doping confirms the magnetic ordering at room temperature in $\mathrm{ZnO}: \mathrm{Sm}$ nanocrystals [38]. As XRD indicate formation of one phase in $\mathrm{ZnO}: \mathrm{Sm}$ samples with change in ' $a$ ' and 'c' lattice parameters and does not show any precipitated phase, it can be inferred that $\mathrm{Sm}$ is incorporated into $\mathrm{ZnO}$ lattice in $\mathrm{Zn}$ substitutional site. Thus observed change in magnetic behavior is occurring solely due to $\mathrm{Sm}$ incorporation in $\mathrm{ZnO}$ lattice. The observed magnetism at room temperature in rare earth $\mathrm{Sm}^{3+}$ doped $\mathrm{ZnO}$ has its origin in magnetic interaction between $\mathrm{Sm}^{3+}$ ions and is intrinsic in nature. The observations strongly suggest that a room temperature diluted magnetic semiconducting oxide has been realized in $\mathrm{Sm}$ doped $\mathrm{ZnO}$. Dilute ferromagnetism has been observed in undoped $\mathrm{ZnO}$ [31], transition metal doped $\mathrm{ZnO}$ [39-44] and $\mathrm{Li} / \mathrm{Na}$ doped $\mathrm{ZnO}[45,46]$. In p-type Sm doped $\mathrm{ZnO}$ thin films [6], ferromagnetism has been reported for 5 to 17 at.\% $\mathrm{Sm}$ doped $\mathrm{ZnO}$ with maximum magnetization of approximately $2.5 \times 10^{-5} \mathrm{emu}$, with paramagnetic behavior at $\mathrm{Sm}$ concentration below 5 at \%, undoped $\mathrm{ZnO}$ being diamagnetic. The defects play a crucial role in origin of magnetic behavior of $\mathrm{ZnO}$ [38].

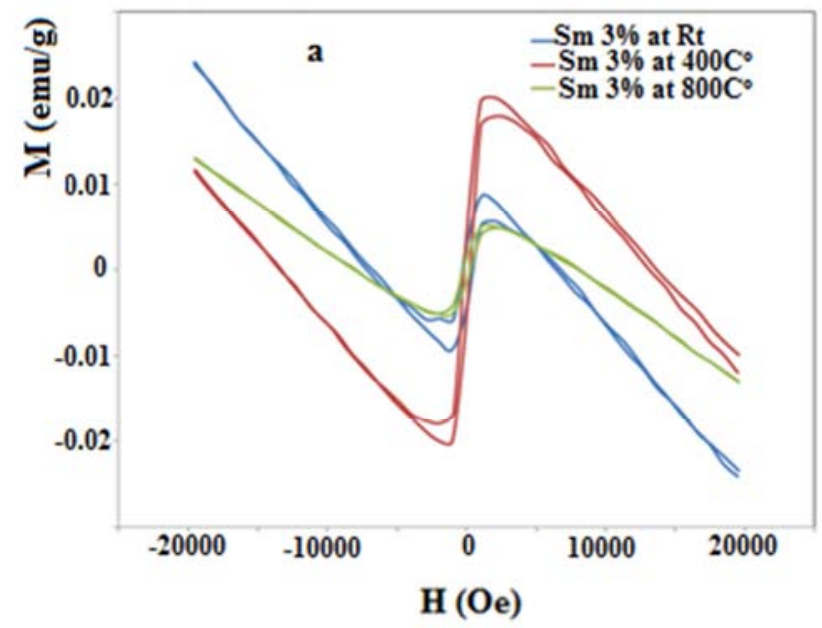

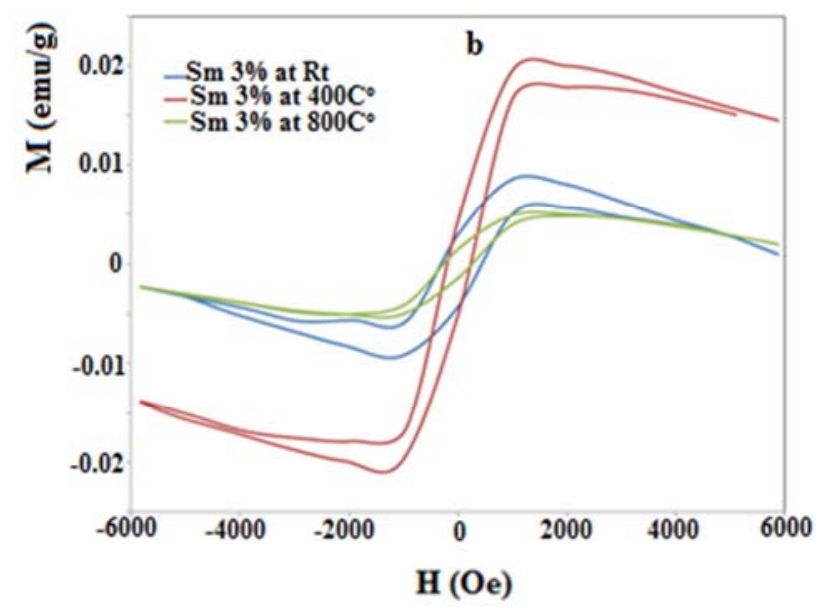

Figure 10. Hysteresis loop of $\mathrm{Zn}_{0.97} \mathrm{Sm}_{0.3} \mathrm{O}$ at $\mathrm{RT}, 400$ and $800^{\circ} \mathrm{C}$ measured at RT with magnetic field at a) 200000 e and b) at 60000 .

Table 2. Magnetic parameters $H_{C}(\mathrm{Oe}), M_{S}(\mathrm{emu} / \mathrm{g})$ and $M_{r}(\mathrm{emu} / \mathrm{g})$ for $\mathrm{ZnO}$ and $\mathrm{ZnO}: \mathrm{Sm}$ system annealed at 100, 400 and $800^{\circ} \mathrm{C}$.

\begin{tabular}{lll}
\hline At RT & & \\
\hline Parameter & $\mathrm{ZnO}$ & $\mathrm{Zn}_{0.097} \mathrm{Sm}_{0.03} \mathrm{O}$ \\
$\mathrm{H}_{\mathrm{C}} \mathrm{Oe}$ & 286 & 1004.8 \\
$\mathrm{M}_{\mathrm{S}}$ emu/g & 0.97327 & $9.15 \times 10^{-3}$ \\
$\mathrm{M}_{\mathrm{r}}$ emu/g & 0.19919 & $2.97 \times 10^{-3}$ \\
Annealing at $400^{\circ} \mathrm{C}$ & & \\
Parameter & $\mathrm{ZnO}$ & $\mathrm{Zn}_{0.097} \mathrm{Sm}_{0.03} \mathrm{O}$ \\
$\mathrm{H}_{\mathrm{C}} \mathrm{Oe}$ & 990 & 1004.8 \\
$\mathrm{M}_{\mathrm{S}}$ emu/g & $2.3 \times 10^{-3}$ & $20 \times 10^{-3}$ \\
$\mathrm{M}_{\mathrm{r}}$ emu/g & $1.9 \times 10^{-3}$ & $4.28 \times 10^{-3}$ \\
$\mathrm{Annealing}^{-3} 800^{\circ} \mathrm{C}$ & & \\
$\mathrm{Parameter}$ & $\mathrm{ZnO}$ & $\mathrm{Zn}_{0.097} \mathrm{Sm}_{0.03} \mathrm{O}$ \\
$\mathrm{H}_{\mathrm{C}} \mathrm{Oe}$ & 312 & 1004.8 \\
$\mathrm{M}_{\mathrm{S}}$ emu/g & $3.4 \times 10^{-3}$ & $5 \times 10^{-3}$ \\
$\mathrm{M}_{\mathrm{r}}$ emu/g & $1.1 \times 10^{-3}$ & $1.6 \times 1^{-3}$ \\
\hline
\end{tabular}

\subsection{2. $E S R$}

Electron spin resonance (ESR) is an effective tool to investigate the oxidation state, electronic configuration and site occupancy of the dopant transition metal ion more critically and also to understand the carrier concentration and magnetic exchange coupling at a microscopic level. As the numbers of unpaired electrons are different in different oxidation states, they can be easily distinguished from the number of fine transitions in the ESR spectra from their gvalues. In addition the ESR technique is very sensitive method for detecting ferromagnetic ordering as well as other magnetic species.

A typical ESR spectrum of pure and doped $\mathrm{ZnO}$ at room temp are shown in Figure $11 \mathrm{a}, \mathrm{b}$ give the signales of $\mathrm{g}$ factor of the system. Symmetric resonance was observed for $\mathrm{ZnO}$ and $\mathrm{Sm} \mathrm{3 \%}$ doped $\mathrm{ZnO}$, and the resonance shifts to a lower field, which corresponds to the increase in g-value. The obvious resonance at around $\mathrm{g}=1.96 \pm 0.002(\mathrm{~g}=1.958$ for pure $\mathrm{ZnO}$ and $\mathrm{g}=1.962$ for $\mathrm{Sm} \mathrm{3 \%}$ doped $\mathrm{ZnO}$ ) is observed. The resonance at $\mathrm{g}=1.960$ is attributed to shallow donors, normally, small donor centers are introduced by some defects or impurities in $\mathrm{ZnO}$ [6, 47-49]. For pure $\mathrm{ZnO}$, there is no resonance at The position at $\mathrm{g}=1.994$ which generally attributed to singly ionized oxygen vacancies. In addition, it 
can be seen that whit doping 3\% sm $\mathrm{g}=1.960$. Therefore, $3 \%$ Sm doping may introduce extra ESR resonance, which may be from Sm doping induced shallow donors. The high $\mathrm{g}$ resonance suggests the ferromagnetic ordering or strong exchange coupling of the magnetic ions. Although the origin of the signal with these g-values are still unclear, it has been demonstrated in the literature that the paramagnetic signal around $\mathrm{g}$ value of 1.96 appears often owing to residual impurities in $\mathrm{ZnO}$ as well as intrinsic defects like oxygen vacancies or $\mathrm{Zn}$ interstitial [6, 50-56].
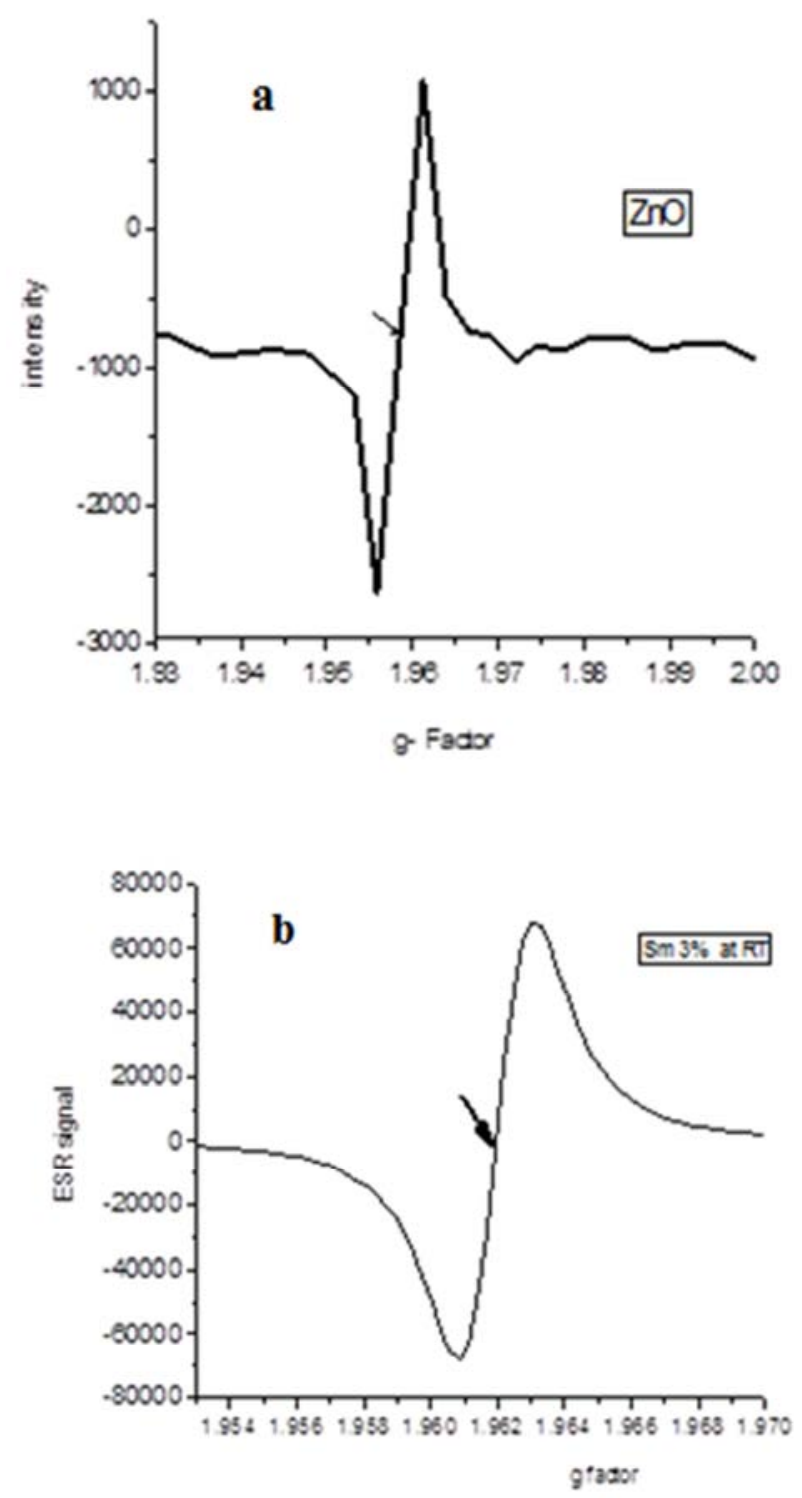

Figure 11. G-factor signals for $\mathrm{ZnO}$ and $\mathrm{ZnO}$ doped $3 \% \mathrm{Sm}$ at room temperature.

\section{Conclusions}

We have successfully synthesized $\mathrm{Sm}$ doped $\mathrm{ZnO}$ nanoparticles with $3 \%$ concentrations by coprecipitation method. The XRD pattern of all the samples showed $\mathrm{ZnO}$ hexagonal wurtzite structure with sharp and intense peaks with small change in lattice parameters due to Sm doping in $\mathrm{ZnO}$, indicating the substitution of $\mathrm{Sm}$ ions for $\mathrm{Zn}$ sites. Magnetic measurements show an enhancement in room temperature ferromagnetism (RTFM) with Sm doping. Ferromagnetic behavior exists over and above the diamagnetic behavior. Undoped $\mathrm{ZnO}$ show super ferromagnetic related to $\mathrm{Zn}$ vacancies, with doping the oxygen vacancies favored in formation than $\mathrm{Zn}$ vacancies so the general behavior is diamagnetic.

\section{References}

[1] A. Wei, L. Pan, W. Huang, Materials Science and Engineering B 176 (2011) 1409.

[2] Z. L. Wang, Adv. Funct. Mater. 18 (2008) 3553.

[3] D. A. Arora, K. Asokan, A. Mahajan, RSC Adv. 6 (2016) 78122.

[4] Y. Liu, W. Luo, R. Li, H. Zhu, X. Chen, Opt. Express 17:12 (2009) 9748.

[5] B. Roy, S. Chakrabarty, O. Mondal, M. Pal, A. Dutta, Mater. Charact., 70 ( 2012) 1.

[6] J. Piao, L. Tseng, J. Yi, Chemical Physics Letters 649 (2016) 19.

[7] T. Dietl, H. Ohno, F. Matsukura, J. Cibert, D. Ferrand, Science 287 (2000) 1019.

[8] B. D. Yuhas, D. O. Zitoun, P. J. Pauzauskie, Angew. Chem. Int. Ed. 45 (2006) 420.

[9] A. J. Kulandaisamy, Ceramics International (2015) (http://dx.doi.org/10.1016/j.ceramint.2015.09.084).

[10] B. Pal, S. Dhara, P. K. Giri, Journal of Alloys and Compounds (2014), doi: (http://dx.doi.org/10.1016/j.jallcom.2014.06.087).

[11] G. Shen, J. H. Cho, S. Jung, and C. J. Lee, Chem. Phys. Lett. $401(2005) 529$.

[12] G. Vijayaprasath, R. Murugan, Ceramics International, (http://dx.doi.org /10.1016/ j.cer amint. 2015.04.160).

[13] J. S. Ruiz, G. Criado, M. H. Chu, Nano Lett., 11 (2011) 5322.

[14] W. An, X. Wu, X. C. Zeng, J. Phys. Chem. C, 112 (2008) 5747.

[15] S. Dhar, O. Brandt, M. Ramsteiner, Phys. Rev. Lett., 94 (2005) 037205 .

[16] D. Wang, Q. Chen, G. Xing, Nano Letters, 12 (2012) 3994.

[17] G. Vijayaprasath, G. Ravi, A. S. Haja Hameed, J. Phys. Chem. C, 118 (2014) 9715.

[18] B. M Abdolmajid, Int. J. Electrochem. Sci; 4 (2009) 247.

[19] Renugadevi et al., IJPSR 3:8 (2012) 2639.

[20] D. Gao, Z. Zhang, J. Fu, Journal of applied physics 105 (2009) 113928

[21] N. H. Hong, J. Sakai, N. Poirot, Phys. Rev. B 73 (2006) 132404 . 
[22] S. Banerjee, M. Mandal, N. Gayathri, Appl. Phys. Lett. 91 ( 2007) 182501.

[23] A. Sundaresan, R. Bhargavi, N. Rangarajan, Phys. Rev. B 74 ( 2006) 161306.

[24] N. H. Hong, J. Sakai, and V. Briz'e, J. Phys.: Condens. Matter 19 ( 2007) 036219.

[25] A. Sundaresan, R. Bhargavi, Phy Rev B; 74 ( 2006) 161306.

[26] S. Kumar, Y. J. Kim, B. H. Koo, Materials Letters 63:2 (2009) 194.

[27] Q. Wang, Q. Sun, G. Chen, Phy Rev B 77 (2008) 205411.

[28] A. Zubiaga, F. Plazaola, Phys. Rev. B 76 (2007) 085202.

[29] N. Rajamanickam, Journal of Alloys and Compounds 614 (2014) 151.

[30] D. Y. Inamdar, A. D. Lad, J. Phys. Chem. C 114 (3) (2010) 1451.

[31] A. Sundaresan, R. Bhargavi, Phys. Rev. B 74 (2006) 161306.

[32] R. N. Aljawfi, F. Rahman, Materials Letters 99 (2013) 18.

[33] Y. Wang, Materials Research Bulletin 83 ( 2016) 408.

[34] J. B. Yi, C. C. Lim, G. Z. Xing, Phys Rev Lett. 104:13 (2010) 137201 .

[35] Y. Wang, X. Luo, Chem Mater. 27:4 ( 2015) 1285.

[36] Y. Wang, J. Piao, G. Xing, Y. Lu, Journal of Materials Chemistry C (2015).

[37] A. G. El Hachimi, H. Zaari, A. Benyoussef, Journal of rare earths 32: 8 (2014) 715 .

[38] S. Chawla, M. Saroha, R. K. Kotnala, Electron. Mater. Lett. 10: 1 ( 2014) 73 .
[39] U. Ozgur, Ya. I. Alivov, C. Liu, J. Appl. Phys. 98 (2005) 041301.

[40] X. S. Wang, Z. C. Wu, J. F. Webb, Appl Phys. A 77 (2003) 561.

[41] S. J. Pearton, C. R. Abernathy, J. Appl. Phys. 93 (2003) 1.

[42] J. M. D. Coye, M. Venkatesan, and, Nature Materials 4 (2005) 173.

[43] T. Dietl, H. Ohno, F. Matsukura, Science 287 (2000) 1019.

[44] K. Jayanthi, S. Chawla, A. Joshi, J. Phys. Chem. C. 114 (2010) 18429.

[45] S. Chawla, K. Jayanthi, Phys. Rev. B 79 (2009) 125204.

[46] S. Chawla, K. Jayanthi, J. Appl. Phys. 106 (2009 113923.

[47] A. Janotti, C. G. V. d. Walle, Phys. Rev. B 76 (2007) 165202.

[48] N. Y. Garces, et al., Appl. Phys. Lett. 80 (2002) 1334.

[49] I. Zutic, J. Fabian, S. C. Erwin, IBM J. Res. Dev. 50 (2006) 121.

[50] T. Tsuji, Y. Terai, M. Kamarudin, 358 (2012) 2443.

[51] T. Ishizuka, Anal. Chem. 45 (1973) 538.

[52] W. M. Jadwisienczak, H. J. Lozykowski, A. J. Electron. Mater. 31 (2002) 776.

[53] X. Q. Meng, J. Lumin. 122 (2007) 766.

[54] K. Samanta, P. Bhattacharya, R. S. Katiyar, Appl. Phys. Lett. 87 (2005) 101903.

[55] H. Y. He, J. Fei, J. Lu, J. Nanostruct. Chem. 5 (2015) 169.

[56] L. T. Tseng, et al., AIP Adv. 4 (2014) 067117. 